\title{
Vascular Biology of Reactive Oxygen Species and NADPH Oxidases: Role in Atherogenesis
}

\author{
Adrian Manea ${ }^{1,2}$ \\ 1"Petru Poni"Institute of Macromolecular Chemistry, Iasi \\ 2"Nicolae Simionescu" Institute of Cellular Biology and Pathology, Bucharest
}

Romania

\section{Introduction}

Eukaryotic cells face constantly the formation of reactive oxygen species (ROS) as a result of their aerobic metabolism. ROS play an important role in the regulation of signal transduction pathways and gene expression but its over-production is acutely harmful to cells, particularly in cardiovascular diseases (CVD) by a mechanism that is not fully understood. Most CVD (the leading cause of mortality in developed countries) entail the focal development of atherosclerotic plaques in response to various deleterious insults that affect the artery wall's cells (Simionescu, 2007). Atheroma may occlude partially or totally the arterial lumen and ultimately, rupture of the vulnerable plaques results in thrombus formation and obstruction of the vessels of vital organs like heart, brain, lung, and kidney. Atheroma formation is characterized by progressive lipid accumulation in the vessel's intima, dysfunctions of endothelial cells (EC) and smooth muscle cells (SMC), and a strong inflammatory reaction with the participation of extravasated immune cells (Fearon \& Faux, 2009). Compelling evidence (including ours) revealed that oxidative stress and NADPH oxidase - derived ROS play the key role in all stages of atherosclerosis and that genetic ablation of various oxidase components protects the cells against the detrimental effects of oxidative stress (Simionescu et al., 2009). Therefore, understanding the molecular mechanisms of ROS formation and function is a prerequisite of an effective anti-oxidative stress therapy.

\section{Reactive oxygen species formation in the vasculature}

As the name indicates, ROS are a class of highly reactive molecules derived from chemical conversion of molecular oxygen $\left(\mathrm{O}_{2}\right)$. ROS are formed in all the aerobic cells and organisms as by-products of metabolic and respiration processes, under the influence of ionizing radiation or produced deliberately by specialized enzyme systems. ROS formation is initiated by reduction of $\mathrm{O}_{2}$ with one electron leading to the formation of short-lived and highly reactive superoxide anion $\left(\mathrm{O}_{2}{ }^{\bullet-}\right)$. Successive reduction of $\mathrm{O}_{2}{ }^{\bullet}$-, protonation or interaction with various converting enzymes gives rise to a large spectrum of molecules with diverse physicochemical characteristics such as $\mathrm{H}_{2} \mathrm{O}_{2}$ and $\mathrm{HO} \bullet$. The dismutation of $\mathrm{O}_{2}{ }^{-}$to $\mathrm{H}_{2} \mathrm{O}_{2}$ can be either spontaneous or catalyzed by specialized enzymes namely, members of the superoxide dismutase family. $\mathrm{H}_{2} \mathrm{O}_{2}$ may be completely reduced to $\mathrm{H}_{2} \mathrm{O}$ by 
means of various peroxidases such as catalase and glutathione peroxidase or partially reduced to $\mathrm{HO} \bullet$, one of the most powerful oxidizing agent identified in biological systems. The generation of $\mathrm{HO} \bullet$ is mediated by various free transition metal ions (e.g., $\mathrm{Fe}^{2+}, \mathrm{Cu}^{2+}$ ) via the Haber-Weiss reaction (Manea, 2010).

Apart from the aforementioned chemical processing of $\mathrm{O}_{2}$, superoxide can react with other molecular species including nitrogen species such as nitric oxide (NO) or polyunsaturated fatty acids. The reaction between $\mathrm{O}_{2}{ }^{--}$and $\mathrm{NO}$ is tightly controlled by the rate of diffusion of both radicals, and result in the formation of ONOO- a potent oxidant. Alternative reactions may led to the generation of mixed reactive oxygen and nitrogen radicals such as nitrogen dioxide radical $\left(\bullet \mathrm{NO}_{2}\right)$ and nitryl chloride $\left(\mathrm{NO}_{2} \mathrm{Cl}\right)$ (Turrens, 2003).

Lipid peroxidation products formation represents an important mechanism whereby ROS elicit physiological and pathophysiological function in the living cells. ROS (especially $\mathrm{HO} \bullet$, - $\mathrm{NO}_{2}$, and ONOO-) may react with polyunsaturated fatty acids present on biological membranes or circulating/infiltrated lipoproteins, a condition that facilitate the formation of fatty acid peroxyl radical (R-COO-) that can further attack adjacent fatty acid chains and trigger the production of other lipid radicals by a chain reaction mechanism (Negre-Salvayre et al., 2010; Riahi et al., 2010; Shao \& Heinecke, 2009).

Tyrosyl radicals produced by myeloperoxidase (MPO) have also been shown to be involved in the initiation of lipid peroxidation (Hazen et al., 1997). In vitro studies revealed that lipid peroxidation occurred only in the presence of free L-tyrosine suggesting that tyrosyl radicals formation by MPO are essential mediators for the initiation of lipid peroxidation and subsequent LDL oxidation by activated human neutrophils, which contain abundant MPO and $\mathrm{H}_{2} \mathrm{O}_{2}$ (Savenkova et al., 1994). Tyrosyl radicals have also been shown to play a role in LDL oxidation in vivo and in atherogenesis. Analysis of LDL isolated from human vascular tissue demonstrated that $0, O^{\prime}$-dityrosine levels were 100 times greater than that observed in circulating LDL. Similarly, $o, o^{\prime}$-dityrosine formation was found to be robust increased in atherosclerotic fatty streaks and in advanced atheromas compared to normal aortic tissue, indicating that tyrosyl radical formation was capable of protein damage in vivo (Leeuwenburgh et al., 1997).

\section{Molecular targets of ROS}

The biological function of ROS is highly regulated by their basic physicochemical properties, cellular compartmentalization and the formation rate. Since $\mathrm{O}_{2} \cdot-$ is a short-lived charged species, it cannot diffuse through biological membranes and acts closeness of the formation site. Nevertheless, an anion channel-dependent plasma membrane transport mechanisms has been demonstrated to play an important role in mediating cell-to-cell communication. Notably, $\mathrm{O}_{2}{ }^{--}$is water-soluble and functions either as an oxidizing agent (e.g., one-electron reduction of $\mathrm{O}_{2}{ }^{\bullet-}$ yields $\mathrm{H}_{2} \mathrm{O}_{2}$ ) or as a reducing agent (e.g., ONOO- formation). $\mathrm{HO} \bullet$ is extremely reactive and does not diffuse more that a few molecular diameters from its site of formation (Touyz, 2003). In contrast, $\mathrm{H}_{2} \mathrm{O}_{2}$ is highly stable under physiological conditions. Being an uncharged molecule, $\mathrm{H}_{2} \mathrm{O}_{2}$ is membrane-permeable and able of activating downstream signalling molecules relatively far from the site of formation.

At low, physiological concentration, ROS modulate key signalling processes initiated by hormones, cytokines, vasoactive agents, blood coagulation factors, and hemodynamic shear stress. Reactive oxygen intermediates react at near-diffusion rate and influence the activity of numerous of signalling molecules including receptors, protein kinases/phosphatases, 
transcription factors, peptides, ion channels and transporters, lipids, carbohydrates, and other oxygen-based species, a process that influence dramatically the cell behavior (Shao \& Heinecke, 2009). The affinity of ROS for a specific substrate is dictated by both physicochemical features of the reactive oxygen intermediates and also of the targeted molecules. In addition, the occurrence and the abundance of specific functional groups, such as iron-sulfur centers, disulfide-bonds, amino and hydroxyl groups or fatty acids doublebonds, greatly influence the chemical interactions between ROS and redox-sensitive biological molecules. As initially showed in microorganisms, eukaryotic cells respond to increased generation of $\mathrm{O}_{2}{ }^{\bullet-}$ and $\mathrm{H}_{2} \mathrm{O}_{2}$ by the up-regulation of various gene products, largely antioxidant enzymes and molecules implicated in the preservation of cellular homeostasis, self-renewal, and reparatory processes. In terms of selectivity, $\mathrm{O}_{2}{ }^{--}$reacts preferentially with the transcription factors and electron transporters in respiratory chains containing iron-sulfur clusters. In contrast, $\mathrm{H}_{2} \mathrm{O}_{2}$ reacts mainly with the disulfide-bonds present on the protein kinases/phosphatases, transcription factors, and ion channels. Additional compelling evidence highlights that the redox-regulation of cell function represents an evolutionary conserved mechanism that alter directly or indirectly the activities of a large spectrum of signaling molecules (Liu et al., 2005).

Protein tyrosine phosphatases (PTPs) are probably the best characterized signaling molecules targeted directly by ROS, especially of $\mathrm{H}_{2} \mathrm{O}_{2}$, owing to the existence of a highly conserved 230-amino-acid domain that contains reactive cysteine, which catalyzes the hydrolysis of protein phosphotyrosine residues. Consequently, a key mechanism whereby $\mathrm{H}_{2} \mathrm{O}_{2}$ controls various cellular processes is determined by the reversible oxidation of PTPs catalytic cysteines that blocks protein dephosphorylation causing transient inhibition of PTPs.

Notably, several members of the protein tyrosine kinases (PTKs) family, including nonreceptor protein tyrosine kinases (i.e., Src, Jak, Pyk) have been shown to be activated in response to cellular redox variations (Tonks, 2006). Nevertheless, the precise molecular mechanisms of PTKs redox regulation are not entirely understood, and it is not clear if the PTK activities are directly correlated with the alterations induced by ROS action on enzyme structures Still, most of the available date suggests that the majority of the effects are attributable to PTP inhibition by ROS rather than PTK oxidation (Tabet et al., 2008).

Another important class of molecules regulated by redox-dependent mechanisms is represented by the mitogen-activated protein kinase (MAPKs) family, that control key physiological processes such as mitosis, differentiation, proliferation, cell survival, and apoptosis. MAPKs are serine/threonine-specific protein kinases which activities are tightly regulated by complex phosphorylation pathways. Emerging evidence demonstrates that in the cardiovascular system, the functions of MAPKs are also influenced by extracellular and intracellular ROS by yet incompletely defined mechanisms (Wu et al., 2008). Apparently, the upstream regulators of MAPKs, namely MAPK kinases (MEKs), PTKs, and PTPs, might be the actual molecular targets of ROS and the genuine sensors of the intracellular redox state changes (Sedeek et al., 2009).

Similar to PTPs, MAPK phosphatases (MKPs) display a highly conserved redox-sensitive cysteine in their catalytic core. Thus, the oxidative inhibition of MKPs may results in the persistent activation of MAPKs, as observed in various developmental or pathological states. Taken together, redox-dependent and as well as redox-independent activation of MAPKs cascades congregate to activate downstream signaling pathway in response to 
hormones, growth factors, pro-inflammatory mediators, and vasoactive agents. Besides MAPKs, the activity of serine/threonine protein kinases Akt and Rho has been indicated to be redox-sensitive and to play a central role in cellular survival pathways (Lee \& Griendling, 2008). Apart from protein kinases/phosphatases and transcription factors, ROS are important regulators calcium homeostasis, by mechanisms that engages reversible thiol oxidation of the cysteine residues present on ion channels and transporters. In the vascular cells ROS, particularly $\mathrm{O}_{2}{ }^{--}$and $\mathrm{H}_{2} \mathrm{O}_{2}$, also enhance intracellular $\mathrm{Ca}^{2+}$ concentrations by increasing the extracellular influx through the plasma membrane channels and mobilization from intracellular stores, and by the inhibition of Ca2+-ATPases located in the plasma membrane and endoplasmic reticulum. The plasma membrane $\mathrm{K}+$ channels have been shown to be redox-sensitive, a process that mediates hyperpolarization-dependent vascular relaxation (Belia et al., 2009; Briones \&Touyz, 2010). These data indicates that the redox status of ion channels and transporters plays an essential role in cell physiology and represents an important determinant of vascular pathology under conditions of the altered production of ROS.

\section{Antioxidant mechanisms in the cardiovascular cells}

ROS are physiologically produced at low concentration during metabolic processes in nonphagocytic cells, by the mitochondrial respiratory chain, cyclooxygenases, lipoxygesases, cytochrome $\mathrm{P} 450$ reductase, xanthine oxidase.

Almost three decades ago, the commonly accepted assumption was that the antioxidant system has developed to defend the cells against the damaging and unavoidable effects of ROS, which are capable to produce irreversible, structural, and functional oxidative damage of DNA, proteins, lipids, and carbohydrates. This theory was supported by many experimental evidence regarding the strategic tissular distribution, expression/concentration levels, and localization of the antioxidants within cellular compartments. Nevertheless, soon after the discovery of enzyme systems that deliberately generates ROS (e.g., NADPH oxidases) under physiological and pathological states, it has become apparent that ROS are not just the by-products of aerobic metabolism, but also important signalling molecules (Forman et al., 2010; Go \& Jones 2010). Therefore, the subtle relationship among oxidizing and reducing agents permits ROS to function as second messengers and to regulate various cellular functions. Thus, besides neutralization of ROS, the antioxidant system has emerged as a critical regulator of the redox-sensitive processes.

The concentration of various oxygen-based reactive intermediates is maintained in physiological range by a very complex antioxidant system comprising both enzymatic ROS scavengers, namely superoxide dismutase, catalase, glutathione peroxidase, thioredoxin, glutaredoxin, peroxiredoxin, heme oxygenase, and paraoxonase, and non-enzymatic ROS quenchers, such as glutathione, vitamins, lipoate, urate, and ubiquinone (Zadák et al., 2009). Superoxide dismutases (SOD) represent a family of enzymes that catalyze the dismutation of $\mathrm{O}_{2}{ }^{-}$- into $\mathrm{O}_{2}$ and $\mathrm{H}_{2} \mathrm{O}_{2}$. Three SOD isoforms are expressed concomitantly in different cellular compartments, including the cytosol (SOD1; Cu/ZnSOD), mitochondria (SOD2; MnSOD), and the extracellular space (SOD3; ecSOD) (Valdivia et al., 2009). Catalase (CAT) is found in peroxisomes where it decomposes $\mathrm{H}_{2} \mathrm{O}_{2}$ to $\mathrm{H}_{2} \mathrm{O}$ and $\mathrm{O}_{2}$. Glutathione peroxidases (GPx) represent a family of isoenzymes encoded by separate genes that differ in cellular distribution pattern and substrate specificity. GPx1, the most abundant isoform, is expressed in the cytosol and has $\mathrm{H}_{2} \mathrm{O}_{2}$ as its main substrate. GPx2 is an extracellular space enzyme, 
while GPx3 is particularly abundant in the plasma. GPx4 has as substrates lipid hydroperoxides and is present at a low level in nearly every cell type. Thioredoxins (TRx) and glutaredoxins (GRx) are proteins that function as antioxidants by enabling the reduction of other proteins by cysteine thioldisulfide exchange. Apart from being involved in antioxidant defense, different isoforms of the TRx and GRx families have been shown to play an important role in regulation of gene expression by redox-dependent processes. Peroxiredoxins (PRx) represent a ubiquitous family of antioxidant enzymes whose activities are tightly regulated by phosphorylation cascades and by changes in the redox and oligomerization states. PRx controls intracellular peroxide levels and mediate signal transduction in cardiovascular cells (Woo et al., 2010).

\section{Role of oxidative stress in atherogenesis}

Physiological production of ROS contribute to the preservation of vascular homeostasis by regulating important biological processes such as cell growth, proliferation, differentiation, apoptosis, cytoskeletal organization, and cell migration. Still, in the last few decades, it has become apparent that overproduction of ROS correlated with alterations of the antioxidant system, vascular inflammation and metabolic dysfunction are key pathological initiators of cardiovascular disorders. Generated in excess, ROS react randomly with all of biological molecules inducing the irreversible alterations of DNA, proteins, carbohydrates, and lipids components, thus altering cell functions (Martinet et al., 2001). As a result, extensive studies have concentrated on the role of oxidative stress-induced cellular dysfunction, redox control of vascular response to inflammatory and metabolic insults, the molecular mechanisms of ROS generation and the means that this class of molecules contributes to vascular damage.

Oxidative stress represents a pathological condition characterized by the incapacity of antioxidant mechanisms to neutralize the deleterious effects of ROS and their metabolites. The means of oxidative stress onset and progression in vascular pathological states, include the overproduction of ROS, changes in the endogenous antioxidant system, and the production of various oxygen intermediates such as ONOO- and $\mathrm{HO}$ - that cannot be efficiently buffered by the naturally occurring antioxidant mechanisms. In addition, spatial and temporal co-expression and co-localization of various enzymatic and non-enzymatic ROS-producing sources at the site of vascular insults may potentially exacerbate predispose to vascular insults and dysfunction (Kondo et al., 2009; Lee et al., 2009).

The importance of oxidative stress in onset and development of atherosclerosis is commonly accepted (Fearon \& Faux, 2009). Still, numerous clinical trials failed to demonstrate that the antioxidant therapy improve the health of patients with cardiovascular diseases (Yusuf et al., 2000). Consequently, many questions arise relative to our current knowledge of the molecular processes implicated in ROS formation and action. Hitherto, different pharmacological approaches have been employed to counteract oxidative stress-induced injury in the cardiovascular system i.e. antioxidant supplements containing vitamins $C$ and $E$, polyphenols or selective inhibitors of distinct sources of ROS (Olukman et al., 2010). Nevertheless, these pharmacological interventions have many disadvantages such as inadequate concentration of active compounds at the site of ROS formation, or vitamins themselves becoming radicals with pro-oxidant activity or not being effective scavengers for various reactive oxygen/nitrogen intermediates, namely hydrogen peroxide $\left(\mathrm{H}_{2} \mathrm{O}_{2}\right)$, peroxynitrite anion (ONOO-), hydroxyl anion $(\mathrm{HO} \bullet)$, and hypochlorous acid $(\mathrm{HOCl})$. 
Excessive ROS formation in atherogenesis triggers a chain of critical events such as EC dysfunction, oxidation of macromolecules especially LDL and extracellular matrix constituents, phenotypic alterations of SMC and macrophage/SMC-derived foam cell and modulate the function of signalling molecules in fibroblasts, which promotes inflammation of vascular adventitia (Sima et al., 2009). Vascular resident cells and transvasated immune cells are important sources of ROS within the atheroma (Heistad et al., 2009). These particularities show that atherosclerosis represents a multifactorial vascular disorder characterized by complex interactions and cross talk between the resident cells of the vascular wall, the cells of the immune system and the factors they produce.

As shown in various animal models of atherosclerosis, oxidative stress is a primary occurrence and a key contributor to endothelial dysfunction portrayed by diminished endothelial NO bioavailability, enhanced endothelial transcytosis, up-regulation of proinflammatory molecules, and the alteration of EC fibrinolytic activity (Dejana et al., 2009; Vendrov et al., 2007). In addition, oxidation of macromolecules especially of LDL (oxLDL) plays a key role in all stages of atherogenesis such as fatty streak formation, development of complex lesion, and plaque rupture. Of particular importance is that oxidative stress contributes, at least in part in the modulation of SMC phenotype switching and ultimately contributes to artery wall thickening. In atherosclerosis, SMCs undergo hypertrophy, produce excess extracellular matrix and inflammatory cytokines, proliferate and migrate from the media towards the vessel's intima.

Clinical evidence highlights that oxidative stress is a characteristic feature of many pathological conditions that predispose to atherosclerotic lesion formation such as hypercholesterolemia, hypertension, and diabetes. However, the precise pathological mechanisms accountable for the installation of oxidative stress are still an unsettled subject. In this context, although not completely validated in humans, oxidative stress may not be the sole causative effect of atherosclerosis and one has to consider the diversity of enzymatic and non-enzymatic sources of ROS, their vascular distribution pattern and subcellular compartmentalization, and complex regulation during various stages of the disease progression (Förstermann, 2008).

\section{Vascular sources of ROS: Role of NADPH oxidases}

Various pathways of ROS generation that can potentially contribute to oxidative stress have been described in the cardiovascular system including non-enzymatic decomposition of various compounds and metabolites (e.g., glucose autoxidation), production of ROS as byproducts of cellular respiration and metabolism (i.e., mitochondrial respiratory chain, lipo-/cyclooxygenases, dysfunctional nitric oxide (NO) synthases, cytochrome P450 reductases, xanthine oxidase), lysosomal enzymes or generated in a highly regulated manner by specialized enzymes (e.g., NADPH oxidases) (Gu et al., 2001; Harrison et al., 2003; Madamanchi et al., 2005; Martinez-Hervas et al., 2010; Zalba et al., 2007).

NADPH oxidases (Nox) represent a family of multi-component enzymes, whose unique biological function is the production of ROS both in physiological and pathological states (Lambeth, 2004). Nox was originally identified and characterized as being a "burst" enzyme in professional phagocytes such as neutrophils and macrophages. In phagocytes, in cooperation with MPO, Nox plays a major role in host defense process against invading pathogens through the production of toxic hypochlorous acid $(\mathrm{HOCl})$, a highly reactive oxidant. During phagocytosis, macrophages also generate significant amounts of NO. As a 
result, the Nox-derived $\mathrm{O}_{2}{ }^{-}$reacts with $\mathrm{NO}$ thus producing ONOO-, an extremely cytotoxic chemical species which directly affect and oxidize biological molecules in invading microorganisms, resulting in molecular alteration and microbial death (El-Benna et al., 2007). The phagocyte-type Nox consists of five subunits: a membrane-associated cytochrome b558, comprising a heavily glycosylated 91-kDa protein (gp91phox; Nox2) and nonglycosylated 22-kDa subunit (p22phox), and three cytosolic regulatory components, p40phox, p47phox, and p67phox. Besides "Phox" components, assembly of Nox in an active complex requires the contribution of a low-molecular-weight GTP-binding protein, Rac1/2 or Rap 1A. In latent cells, the Nox complex is dissociated but is rapidly assembled and activated following the exposure to pathogens or inflammatory mediators. Serine phosphorylation of p47phox represents the limiting step of Nox activation and triggers complex formation of cytosolic subunits followed by translocation to the membrane and association with cytochrome b558 (Hoyal et al., 2003; Lassègue \& Griendling 2002; Li \& Shah 2003;). Other than Nox2, macrophages also express Nox1 and Nox4 as inducible isoforms that, reportedly mediate LDL oxidation in the vascular wall (Lee et al., 2009; Maitra et al., 2009).

The expression of functionally active Nox subtypes has been reported in non-phagocytes, including cardiovascular cells. Thus far, the members of the Nox enzyme family consists of seven isoforms (Nox1-5, Duox1/2), each with a particular cell and tissue distribution. Nox enzymes are broadly divided into three major categories, as a function of the extra catalytic domains to the phagocyte-type subunit Nox2. The first group includes Nox1, Nox3, and Nox4 isoforms, which display a number of similarities with Nox2, for instance their structural organization and molecular weight. Besides Nox2-type catalytic core, Nox5, the second group of the Nox family, possess an extra amino-terminal calmodulin-like domain that contains four $\mathrm{Ca}^{2+}$-binding EF-hands structures (Lambeth, 2007). Thus far, four splice variants of Nox 5 , namely Nox $5 a$, Nox $5 \beta$, Nox $5 \gamma$, and Nox $5 \delta$, have been identified in humans. In particular, the Nox5 gene is not present in the rodents' genome. A third class of of Nox is represented by the Nox5-like dual oxidases (Duox) which possess, in addition to the Nox5-type structure, an extracellular peroxidase domain that uses the $\mathrm{H}_{2} \mathrm{O}_{2}$ generated by its Nox catalytic core. For their function, all the Nox1-4 subtypes necessitate the p22phox component, while Nox5 and Duox are activated directly by calcium. As shown in aortic SMCs, activation of Nox1 requires the participation of a ClC-3 anion transporter. The anion transporter co-expresses with Nox1 in early endosomes and is required for charge neutralization of the electron flow generated by Nox1 across the membrane of signalling vesicles (Miller et al., 2007). Nox4 is constitutively active and its activity is supported by the association with p22phox, required for the electron transfer, and polymerase delta interacting-protein 2 (Polidp2), that apparently may serve to stabilize the enzymatic complex (Lyle et al., 2009). The activities of Nox1, Nox2, and Nox3 isoforms are highly controlled by phosphorylation reactions involving regulatory subunits that initiate the assembly of Nox into an active enzymatic complex. Other than p40phox, p47phox, and p67phox cytosolic regulatory components, two different structurally related proteins have been discovered in non-phagocyte, specifically Nox organizer 1 (Noxo1), which is an analog of p47phox, and Nox activator 1 (Noxa1), which is an analog of p67phox. Despite the structural similarities, dissimilar functional aspects are involved in the regulation of enzyme activity. For instance, different to p47phox, which in the resting cells is located in the cytosol, Noxo1 is pre-localized at the membrane jointly with Nox1 and p22phox (Lambeth, 
2004). Different subtypes of the Nox enzyme family along with their regulatory proteins are expressed in the cardiovascular cells (i.e., ECs, SMCs, vascular and cardiac fibroblasts, cardiac myocytes, and pericytes), and in circulating immune cells interacting with the blood vessels (i.e., monocytes/macrophages, neutrophils, lymphocytes, platelets, dendritic cells) (Manea et al., 2005).

Nox subtypes are differentially located within the cellular compartments, suggesting a specific correlation between Nox subtypes, subcellular distribution and their specific function to control precise ROS-mediated signal transduction cascades. For instance, Nox1 and Nox2 were detected in caveolae, in the plasma membrane, and endosomes. Nox4 has been detected in focal adhesions, mitochondria endoplasmic reticulum, and the nucleus (Ago et al., 2010; Kuroda \& Sadoshima, 2010). Nox5 is present in the perinuclear regions, endoplasmic reticulum, and in the plasma membrane (BelAiba et al., 2007; Fulton, 2009).

\section{Involvement of Nox enzymes in atherogenresis}

Studies in cell culture and transgenic/knockout mice provided most of the existing data concerning the role of Nox-dependent oxidative stress in atherosclerosis. Nox activity is upregulated by numerous factors linked to atherosclerotic lesion formation and progression namely, inflammatory cytokines (tumor necrosis factor $a$, interferon $\gamma$ ), vasoactive agents (angiotensin II, endothelin 1), metabolic factors (high glucose, modified proteins/lipoproteins/lipids, homocysteine), growth factors (platelet-derived growth factor), coagulation factors (thrombin), and pathological shear stress (Chung et al., 2010; Hwang et al., 2003). Apart from direct detrimental effects, compelling data exists that Noxderived ROS interact and stimulate other enzymatic sources of oxygen/nitrogen reactive intermediates, and generally amplify the initial response to insults (Cohena \& Tong, 2010; Schrader \& Fahimi, 2006).

It is generally accepted that Nox-derived ROS cooperate, and act in concert with other pathological factors leading to vascular inflammation and injury, and that genetic ablation of various Nox subunits (i.e., p47phox, Nox1, Nox2) defends the vascular cells against the harmful effects of oxidative stress. ApoE-/- mice, which develop atherosclerotic lesions that cover the entire range of human lesions (i.e., fatty streaks, intermediate lesions, fibrous plaques, and vulnerable plaques exhibiting necrotic core and intra-plaque hemorrhage) have been extensively used to investigate the role of Nox enzymes in atherogenesis (Nakashima et al., 1994). Using this animal model, it has become evident that enhances in Nox activity and expression occur early in atherogenesis, and hyperactivity of Nox associated with the up-regulation of various isoforms marks all the stages of the plaque formation (Fenyo et al., 2011).

In contrast, ApoE/p47phox double-knockout mice display significantly less atherosclerotic lesions compared with ApoE-/- mice. In the same line, aortic $\mathrm{O}_{2} \cdot$ - levels have been shown to be are lower in p47phox-/- mice than in wild-type mice. In addition, aortic SMCs from p47phox-/- mice exhibit a decreased proliferative response to growth factors compared with that of the SMCs of wild-type mice (Vendrov et al., 2007).

Accelerated atherosclerosis represents a major vascular complication of diabetes mellitus and is responsible for $70-80 \%$ of deaths in diabetic patients in developed and developing countries. Numerous reports revealed that the Nox expression and activity are significantly up-regulated in the vasculature of diabetic subjects, and are associated with the 
development of atherosclerosis and microvascular diseases (retinopathy, neuropathy, and nephropathy). In addition, Nox1, Nox2, and Nox4 are activated and up-regulated in the blood vessels of diabetic animals (Ding et al., 2007; Xu et al., 2007).

Hyperglycemia, the primary clinical manifestation of diabetes, contributes at least in part to diabetic complications by inducing Nox and the ensuing oxidative stress. Moreover, advanced glycation end-products (AGEs), a direct consequence of the high and persistent blood glucose level, are also important inducers of Nox-derived ROS in vascular cells in diabetes. Besides hyperglycemia, hyperinsulinemia contribute to aberrant ROS production and vascular wall dysfunction. Since Nox is one of the main triggers of oxidative stress, it has a prominent role in the pathology of diabetes-induced vasculopathy (Gao \& Mann, 2009). These data make Nox enzymes potential therapeutic targets to counteract the deleterious effects of ROS in diabetes.

Hypertension represents a major risk factor for atherosclerosis and its complications and several reports highlight that oxidative stress is both cause and consequence of hypertension (Briones \& Touyz, 2010). Nox1 deficiency in mice reduces angiotensin II (Ang II) -dependent blood pressure, media hypertrophy, and extracellular matrix deposition, but not cell proliferation (Gavazzi et al., 2007; Matsuno et al., 2005). In agreement with these data, AngII-treated mice overexpressing Nox1 in vascular smooth muscle cells exhibit an increase of blood pressure, a condition that is associated with medial hypertrophy and significant production of ROS (Dikalova et al., 2005). Furthermore, overexpression of Nox1 in vascular SMCs leads to enhanced responsiveness to Ang II causing up-regulation of ROS, eNOS uncoupling and the consequent decline in NO bioavailability, followed by impaired vascular relaxation (Dikalova et al., 2010).

Consistent with these reports, compared with wild-type mice, Nox2 ablation (Nox2-/-) diminishes robustly ROS-mediated protein oxidation, neointimal formation, SMCs proliferation and leukocyte accumulation, indicating that Nox2-mediated signalling and oxidation has a requisite role in the cell response to injury (Chen et al., 2004).

The role of Nox4 and Nox 5 enzymes in atherogenesis is less investigated and consequently, not entirely elucidated, since there are few atherosclerosis-related studies conducted on Nox4 deficient mice, and the Nox 5 gene is not present in the rodent's genome. Thus, most of the current data are provided by studies performed in vitro on various cell-types and isolated tissues.

Recently, a Nox4 deficient mouse model and a cardiomyocyte-targeted Nox4-transgenic model have been developed to investigate the role of Nox4 during cardiac stress. (Zhang et al., 2010). One of the main breakthroughs of this study is that in contrast to the effects of generated by activated Nox1 or Nox2, the up-regulation cardiomyocyte Nox4 results in protection against pressure overload-induced adverse cardiac remodeling. The authors conclude that Nox4 facilitates the maintenance of myocardial capillary density during pressure overload by regulating stress-induced cardiomyocyte hypoxia inducible factor-1 activation and release of vascular endothelial growth factor, resulting in increased paracrine angiogenic activity. In addition, unlike Nox1, Nox2 or Nox5, it seems that Nox4 produces directly $\mathrm{H}_{2} \mathrm{O}_{2}$ and thus is incapable of scavenging $\mathrm{NO}$ or producing ONOO-.

The beneficial effects of Nox4-derived ROS were also reported by means of a newly developed transgenic mouse with endothelial-specific Nox4 overexpression (Ray et al., 2011). The authors showed that vascular segments and endothelial cells of these animals had 
a significant increase in $\mathrm{H}_{2} \mathrm{O}_{2}$ generation rather that $\mathrm{O}_{2}{ }^{-}$and a significant augmentation of the pro-oxidative status. Despite of these aspects, the blood pressure of the animals was lower under basal conditions and after angiotensin II treatment. Interestingly, endotheliumdependent relaxation was significantly improved compared with wild-type animals. Notably, these effects were sensitive to the ex vivo addition of catalase and in vivo administration of $\mathrm{N}$-acetylcysteine, indicating that they were mediated by peroxide-type, namely $\mathrm{H}_{2} \mathrm{O}_{2}$, mechanisms. Mechanistically, it seems that an $\mathrm{H}_{2} \mathrm{O}_{2}$ action on potassium channels may be responsible for the elaboration of endothelium-derived hyperpolarizing factor (EDHF) type. Thus, one has to ponder that the type of ROS released in the vascular system determines their biological function.

As mentioned above, less is know about the role of Nox 5 in atherogenesis, and this is due mainly to the absence of Nox5 gene in the rodents' genome and therefore to the lack of a reliable animal model., Still, it has been reported a significant correlation between Nox5 expression and atherosclerotic lesion progression. Interestingly, a specific expression pattern was reported; with Nox 5 being expressed mainly by the endothelium in the early stages of the disease while its expression is significantly increased in SMCs underlying fibro-lipid atherosclerotic lesions (Guzik et al., 2008).

\section{Mechanisms of Nox regulation}

\subsection{Phosphorylation pathways and transcription factors}

Nox activity and expression is highly regulated at multiple levels by various physiologic and pathological factors which, by this means, dictate the enzyme complex function. The activities of both Nox1 and Nox2 isoforms are primarily regulated by complex networking of phosphorylation cascades involving regulatory components (i.e., p40phox, p47phox, p67phox, Noxo1, Noxa1) which induce the assembly of the enzyme complex. Nox4 is constitutively active and does not necessitate phosphorylation of regulatory proteins, whereas Nox5 has been demonstrated to be $\mathrm{Ca}^{2+}$-responsivenes. Yet, activation mechanisms involving protein kinase $\mathrm{C}$ and the proto-oncogenic tyrosine kinase c-Abl phosphorylation of Nox5 have been reported (El Jamali et al., 2008; Serrander et al., 2007).

The phosphorylation mechanisms responsible for Nox1 and Nox2 activation consist of a large spectrum of signalling molecules such as protein kinase $\mathrm{C}(\mathrm{PKC})$, phosphatidylinositol 3-kinase (PI3K), GTP-binding proteins (Ras, Rac1/2), members of the mitogen-activated protein kinase (MAPK) family (p38MAPK, ERK1/2), phospholipases (PLC $\beta / \gamma$, PLD), arachidonic acid metabolites, and non-receptor protein tyrosine kinases (Kilpatrick et al., 2010; Yamamori et al., 2004). Besides the aforementioned kinases, chaperone proteins (e.g., protein disulfide isomerase) have been proved to be important regulators on Nox function (Janiszewski et al., 2005).

In addition to the phosphorylation of cytosolic regulatory subunits, alterations of the Nox isoforms expression have been shown to be critical for their activity. Multiple transcription factors are coordinately implicated in the modulation of Nox expression and function. PU.1, Elf-1, IRF-1 (interferon regulatory factor-1), and ICSBP (interferon consensus sequence binding protein) are important transcriptional regulators of Nox2 in the myelomonocytic cell lineage (Kakar et al., 2005). In human colon epithelial Caco-2 cells, GATA-binding factors are critical for Nox1 transcriptional activity (Brewer et al., 2006), whereas in murine macrophages, the up-regulation of Nox1 in response to lipopolysaccharide (LPS) 
stimulation is mediated at least in part, by pro-inflammatory transcription factors CCAAT/enhancer-binding protein (C/EBP) $\beta$ and C/EBPS (Maitra et al., 2009).

In previous studies, we have shown that in human aortic SMCs exposed angiotensin II or tumor necrosis factor- $\alpha$, the pro-inflammatory transcription factor AP-1 is an essential regulator of the genes coding for p22phox, Nox1, and Nox4 components (Manea et al., 2008; Raicu \& Manea, 2010). Other than, activator protein -1 (AP-1), the vascular inflammationrelated and growth-promoting transcription factors signal transducer and activator of transcription (STAT1 and STAT3) proteins physically interact with the promoters of human Nox1 and Nox4 genes in SMCs exposed to interferon (IFN) $\gamma$ and a Jauns kinase (Jak)/STAT-dependent mechanisms are implicated in the ensuing $\mathrm{O}_{2}{ }^{\bullet-}$ production. Moreover, the promoter activities of the genes coding for p22phox, p47phox, and p67phox, have been demonstrated to be considerably augmented in SMCs overexpressing STAT1/STAT3, a result that suggests the existence of functionally gamma activated sequence (GAS)/interferon-stimulated response element (ISRE) consensus sequences (Manea et al., 2010a). In human aortic SMCs, Ets1, a critical mediator of vascular inflammation and remodelling, regulates p47phox expression in response to AngII (Ni et al., 2007). Similar observations were made in A7r5 cells and primary mouse aortic SMCs, in which the growth-promoting transcription factor E2F actually interacts and controls the Nox4 transcriptional program (Zhang et al., 2008).

In atherosclerosis, and other major cardiovascular disorders, nuclear factor kB (NF-kB) signalling represents a critical regulating mechanism involved in disease onset and progression, including inflammation, cell proliferation, migration, differentiation and apoptosis. Several line of evidence indicate that NF-kB is a redox-sensitive transcription factor which is robustly activated by ROS possible generated by activated Nox. Interestingly, a positive feed-back loop of Nox activation by NF-kB has been proposed in several studies. Thus, a new integrative concept has emergedthe "vicious cycle", to describe the interconnection between metabolic dysfunction, inflammation, and oxidative stress that converges to vascular disorders (Manea, 2010). In murine monocytes, the expression of the Nox2 is induced by NF-kB. Moreover, the up-regulation of p47phox and p22phox expression by LPS/IFNY was blunted in IkBa-overexpressing cells suggesting the involvement of the NF-kB signaling in the regulation of the Nox components (Anrather et al. 2006). Similar finding were reported in human monocytes/macrophages exposed to TNFa (Gauss et al., 2007). Moreover, in previous studies we have shown that, NF-kB is an important transcriptional regulator of the genes coding for p22phox, Nox1, and Nox4, and has a profound impact in the up-regulation of Nox activity in TNFa-treated human aortic SMCs (Manea et al., 2007; Manea et al., 2010b).

The molecular mechanisms that facilitate hypoxia sensing and related signalling events are critical for the maintenance of vascular cell homeostasis. Compelling data depicts that hypoxic conditions up-regulate the expression and activity various Nox subtypes (Goyal et al., 2004). It has been demonstrated that persistent hypoxia induces Nox4 gene and protein expression levels in pulmonary artery SMCs and in pulmonary vessels in mice exposed to hypoxic conditions (Diebold et al., 2010). Mechanistically, the response is dependent on hypoxia inducible factor-1a (HIF-1a), which interacts with the corresponding elements in the Nox4 promoter. As a result, the HIF-1a dependent upregulation of Nox4 by may be an essential mechanism to preserve ROS level after hypoxia and the hypoxia-induced proliferation of pulmonary artery SMCs. Furthermore, 
activating transcription factor-1 (ATF-1), a transcription factor of the CREB (CRE-binding protein)/ATF family, proved to play a key role in the induction of Nox1 in rat vascular SMCs (Katsuyama et al., 2005).

Nuclear factor (erythroid-derived 2)-like 2, also known as Nrf2 represents a master modulator of the antioxidant responses by inducing genes (e.g., Sod genes) with important function in combating oxidative stress. Interestingly, it has been demonstrated that Nrf2, also controls Nox4 expression in mouse lung and human lung endothelium in response to hyperoxia (Pendyala \& Natarajan, 2010).

\subsection{Genetic and epigenetic mechanisms of Nox regulation}

Genetic studies highlight that several Nox-related polymorphisms are closely associated with an increased susceptibility for cardiovascular disorders. One of the most investigated genes from the Nox complex is CYBA which encodes the p22phox essential subunit. The p22phox is ubiquitously expressed in cardiovascular cells and forms stable and functional heterodimers with Nox1, Nox2 or Nox4, a critical structure for enzyme activity as shown by studies employing siRNA technology to knock-down p22phox expression (Kawahara et al., 2005). Moreover, it has been demonstrated that p22phox is more abundant in advanced atherosclerotic plaques than in nonatherosclerotic arteries, suggesting a correlation between p22phox expression, $\mathrm{O}_{2}{ }^{\circ}$ - production, and the severity of atherosclerosis (Azumi et al., 1999).

The occurrence of particular polymorphisms of the CYBA gene has been shown to predispose to oxidative stress and to be independently correlated with cardiovascular risk factors and disease occurrence namely hypertension, coronary artery disease, myocardial infarction, cerebrovascular disease, diabetic and non-diabetic nephropathy) (San José et al., 2008). Various CYBA allelic variants were detected in both exonic sequences such as C242T, A640G, C549T (Dinauer et al., 1990; Guzik et al., 2000; Inoue et al., 1998), and promoter regions namely $-930 \mathrm{~A} / \mathrm{G},-675 \mathrm{~A} / \mathrm{T},-852 \mathrm{C} / \mathrm{G},-536 \mathrm{C} / \mathrm{T}$ (Lim et al., 2006; Moreno et al., 2007), which potentially affect the p22phox expression and consequently the Nox activity. Thus far, data indicating the existence of functional Nox1-5 polymorphisms with a relevant impact on vascular pathology are not available yet.

Emerging evidence demonstrates that epigenetic events such as DNA methylation and modifications of histone tails are important processes of oxidative stress onset. DNA methylation mechanisms of the promoter $\mathrm{CpG}$ islands has been shown to be involved in the up-regulation of 15-lipoxygenase, a pro-oxidative enzyme with implications in plaque formation and vulnerability, and down-regulation of superoxide dismutase 3, endothelial NO synthase, and various anti-proliferative genes (estrogen receptor- $\alpha$ ), a condition that leads to oxidative stress, impaired vascular relaxation, and aberrant SMC hyperplasia (Fernandez et al., 2010). Hitherto, data about the role of epigenetics in the regulation of Nox subtypes are missing. Nevertheless, using both in vitro (e,g., human aortic SMCs exposed to pro-inflammatory conditions) and in vivo (ApoE-/- mice fed a high fat, cholesterol rich diet) models, we have found recently that an aberrant methylation of the Nox1 promoter may be responsible for the up-regulated expression and activity of this enzyme (Manea et al., unpublished data).

A schematic representation of the key molecular pathways implicated in the up-regulation of Nox enzymes as well as the potential pharmacological targets intended to counteract oxidative stress are presented in the figure below. 


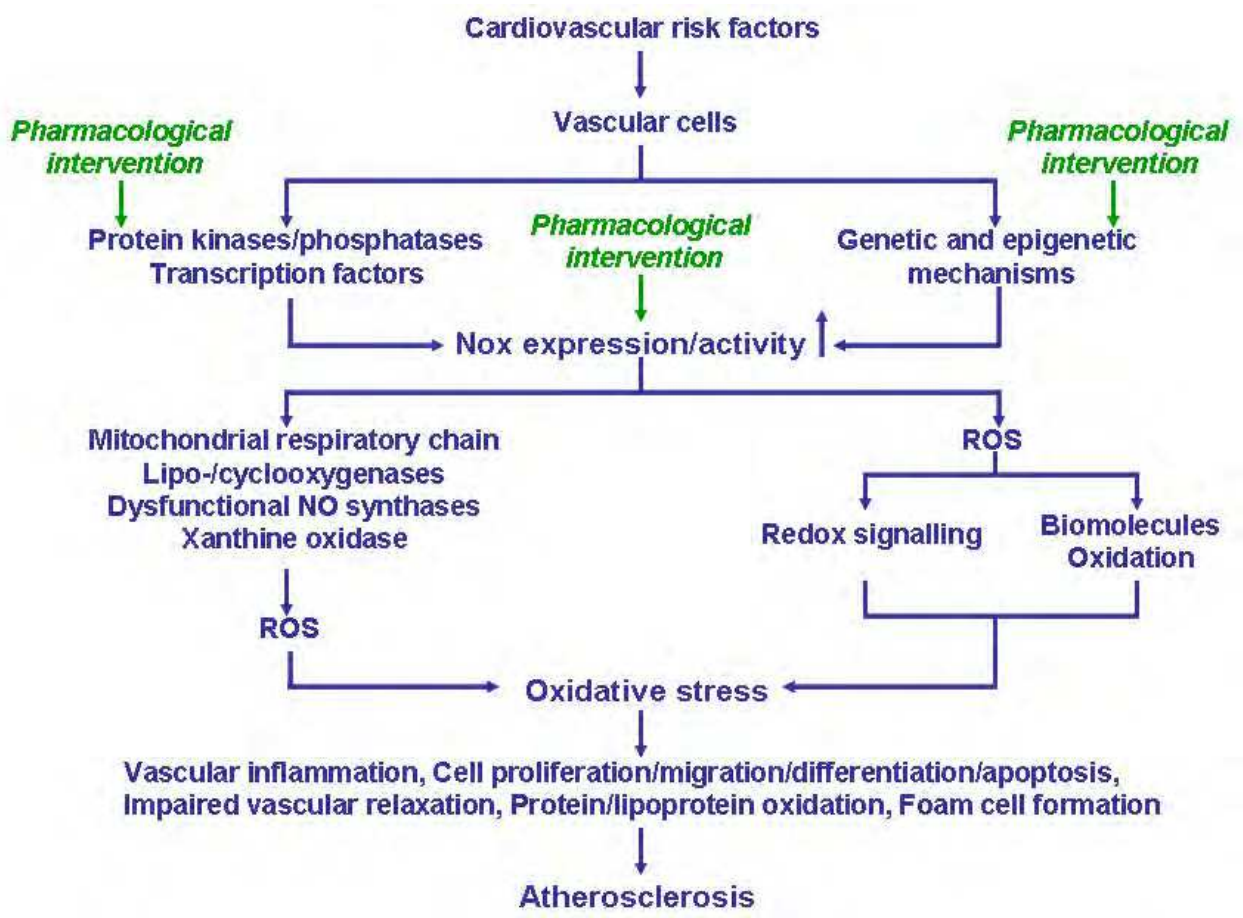

Fig. 1. Schematic depiction of the major mechanisms responsible for the up-regulation of Nox enzymes and installation of oxidative stress in atherosclerosis. In response to cardiovascular risk factors, vascular cells through their receptors activate a range of signalling pathways that up-regulate Nox expression, activity, and the ensuing ROS production. This triggers a chain of critical events that generally amplify the initial response to vascular insults (i.e., activation of other cellular sources of ROS and redox-sensitive signalling effectors). Persistent Nox activation leads to oxidative stress that is a major contributor to the initiation and the development of atherosclerotic lesions. The diagram highlights that genetic, epigenetic, as well as genetic/non-epigenetic-independent mechanisms linked to Nox up-regulation and hyperactivity in atherosclerosis may be used to target and control pharmacologically the Nox-derived oxidative stress (green text).

\section{Conclusion}

The Nox-derived ROS may have both beneficial and deleterious effects. Thus, we can safely assume that these effects are function of the expression pattern and regulation of various Nox isoforms, their subcellular compartmentalization, and the rate of ROS generation. Despite of the numerous existing data, the precise mechanisms of Nox regulation in atherosclerosis and the stream of signalling molecules (up-, or down-regulated) responsible for the increased oxidative stress that is associated with the onset and development of cardiovascular dysfunction, is poorly understood. Thus, a complex interplay of genetic, epigenetic and non-epigenetic factors, transcription factors, co-activators, and/or corepressors may be coordinately involved in the up-regulation of Nox activity in 
atherogenesis. Therefore, elucidation of the complex interactions among different mechanisms that control Nox subtypes expression/activity and subcellular compartmentalization of ROS production and its subsequent biological meaning, may lead to a more focused and effective antioxidant therapies. The expected impact of these pharmacological strategies goes well beyond the atherosclerosis field. Oxidative stress is a common occurrence in most pathologies i.e. diabetes, neurodegenerative diseases, cancer, etc. The knowledge gained will be applicable to all these pathologies since controlling oxidative stress ought to have a beneficial knock-on effect on these diseases. Identifying the basic molecular mechanism regulating the oxidative stress will be used to find ways to manage its occurrence and correct its adverse effects.

\section{Acknowledgement}

This work was supported by grants from the Romanian Ministry of Education, and Research (CNCSIS-UEFISCSU project numbers PNII-IDEI 1005/2009 and PNII-TE 65/2010), and from the European Foundation for the Study of Diabetes - New Horizons. The financial support of European Social Fund - „Cristofor I. Simionescu” Postdoctoral Fellowship Programme (ID POSDRU/89/1.5/S/55216), Sectoral Operational Programme Human Resources Development 2007 - 2013 is acknowledged.

\section{References}

Ago, T., Kuroda, J., Pain, J., Fu, C., Li, H. \& Sadoshima, J. (2010). Upregulation of Nox4 by hypertrophic stimuli promotes apoptosis and mitochondrial dysfunction in cardiac myocytes. Circulation Research, 106, 1253-1264, ISSN 0009-7330

Anrather, J., Racchumi, G. \& Iadecola, C. (2006). NF-kappaB regulates phagocytic NADPH oxidase by inducing the expression of gp91phox. Journal of Biological Chemistry, 281, 5657-5667, ISSN 0021-9258

Azumi, H., Inoue, N., Takeshita, S., Rikitake, Y., Kawashima, S., Hayashi, Y., Itoh, H. \& Yokoyama, M. (1999). Expression of NADH/NADPH oxidase p22phox in human coronary arteries. Circulation, 100, 1494-1498, ISSN 0009-7322

BelAiba, R.S., Djordjevic, T., Petry, A., Diemer, K., Bonello, S., Banfi, B., Hess, J., Pogrebniak, A., Bickel, C. \& Görlach, A. (2007). NOX5 variants are functionally active in endothelial cells. Free Radical Biology and Medicine, 42, 446-459, ISSN 0891-5849

Belia, S., Santilli, F., Beccafico, S., De Feudis, L., Morabito, C., Davi, G., Fanò, G. \& Mariggiò, M.A. (2009). Oxidative-induced membrane damage in diabetes lymphocytes: effects on intracellular $\mathrm{Ca}(2+)$ homeostasis. Free Radical Biology and Medicine, 43, 138-148, ISSN 0891-5849

Brewer, A.C., Sparks, E.C. \& Shah, A.M. (2006). Transcriptional regulation of the NADPH oxidase isoform, Nox1, in colon epithelial cells: role of GATA-binding factor(s). Free Radical Biology and Medicine, 40, 260-274, ISSN 0891-5849

Briones, A.M. \& Touyz, R.M. (2010). Oxidative stress and hypertension: current concepts. Current Hypertension Reports, 12, 135-142, ISSN 1522-6417

Chen, Z., Keaney, J.F. Jr., Schulz, E., Levison, B., Shan, L., Sakuma, M., Zhang, X., Shi, C., Hazen, S.L. \& Simon, D.I. (2004). Decreased neointimal formation in Nox2-deficient mice reveals a direct role for NADPH oxidase in the response to arterial injury. 
Proceedings of the National Academy of Sciences USA, 101, 13014-13019, ISSN 00278424

Chung, S.W., Park, J.W., Lee, S.A., Eo, S.K. \& Kim, K. (2010). Thrombin promotes proinflammatory phenotype in human vascular smooth muscle cell. Biochemical and Biophysical Research Communications, 396, 748-754, ISSN 0006-291X

Dejana, E., Simionescu, M. \& Wolburg, H. (2009). Endothelial cell biology and pathology. Cell and Tissue Research, 335, 1-3, ISSN 0302-766X

Diebold, I., Petry, A., Hess, J. \& Görlach, A. (2010). The NADPH oxidase subunit NOX4 is a new target gene of the hypoxia-inducible factor-1. Molecular Biology of the Cell, 21, 2087-2096, ISSN 1059-1524

Dikalova, A., Clempus, R., Lassègue, B., Cheng, G., McCoy, J., Dikalov, S., San Martin, A., Lyle, A., Weber, D.S., Weiss, D., Taylor, W.R., Schmidt, H.H., Owens, G.K., Lambeth, J.D. \& Griendling, K.K. (2005). Nox1 overexpression potentiates angiotensin II-induced hypertension and vascular smooth muscle hypertrophy in transgenic mice. Circulation, 112, 2668-2676, ISSN 0009-7322

Dikalova, A.E., Góngora, M.C., Harrison, D.G., Lambeth, J.D., Dikalov, S. \& Griendling, K.K. (2010). Upregulation of Nox1 in vascular smooth muscle leads to impaired endothelium-dependent relaxation via eNOS uncoupling. American Journal of Physiology Heart and Circulatory Physiology, 299, 673-679, ISSN 0363-6135

Dinauer, M.C., Pierce, E.A., Bruns, G.A., Curnutte, J.T. \& Orkin, S.H. (1990). Human neutrophil cytochrome b light chain (p22-phox). Gene structure, chromosomal location, and mutations in cytochrome-negative autosomal recessive chronic granulomatous disease. Journal of Clinical Investigation, 86, 1729-1737, ISSN 00219738

Ding, H., Hashem, M. \& Triggle, C. (2007). Increased oxidative stress in the streptozotocininduced diabetic apoE-deficient mouse: changes in expression of NADPH oxidase subunits and eNOS. European Journal of Pharmacology, 561, 121-128, ISSN 0014-2999

El Jamali, A., Valente, A.J., Lechleiter, J.D., Gamez, M.J., Pearson, D.W., Nauseef, W.M. \& Clark, R.A. (2008). Novel redox-dependent regulation of NOX5 by the tyrosine kinase c-Abl. Free Radical Biology and Medicine, 44, 868-881, ISSN 0891-5849

El-Benna, J., Dang, P.M. \& Gougerot-Pocidalo, M.A. (2007). Role of the NADPH oxidase systems Nox and Duox in host defense and inflammation. Expert Review of Clinical Immunology. 3, 111-115, ISSN 1744-666X

Fearon, I.M. \& Faux, S.P. (2009). Oxidative stress and cardiovascular disease: novel tools give (free) radical insight. Journal of Molecular and Cellular Cardiology, 47, 372-381, ISSN 0022-2828

Fenyo, I.M., Florea, I.C., Raicu, M. \& Manea, A. (2011). Tyrphostin AG490 reduces NAPDH oxidase activity and expression in the aorta of hypercholesterolemic apolipoprotein E-deficient mice. Vascular Pharmacology, 54, 100-106, ISSN 1537-1891

Fernandez, Z., Siebel, A.L. \& El-Osta, A. (2010). Atherogenic factors and their epigenetic relationships. International Journal of Vascular Medicine, doi:10.1155/2010/437809

Forman, H.J., Maiorino, M. \& Ursini, F. (2010). Signaling functions of reactive oxygen species. Biochemistry, 49, 835-842, ISSN 0006-2960 
Förstermann, U. (2008). Oxidative stress in vascular disease: causes, defense mechanisms and potential therapies. Nature Clinical Practice Cardiovascular Medicine, 5, 338-349, ISSN 1743-4297

Fulton, D.J. (2009). Nox5 and the regulation of cellular function. Antioxidants and Redox Signaling, 11, 2443-2452

Gao, L. \& Mann, G.E. (2009). Vascular NAD(P)H oxidase activation in diabetes: a doubleedged sword in redox signalling. Cardiovascular Research, 82, 9-20, ISSN 0008-6363

Gauss, K.A., Nelson-Overton, L.K., Siemsen, D.W., Gao, Y., DeLeo, F.R. \& Quinn, M.T. (2007). Role of NF-kappaB in transcriptional regulation of the phagocyte NADPH oxidase by tumor necrosis factor-alpha. Journal of Leukocyte Biology, 82, 729-741, ISSN 0741-5400

Gavazzi, G., Deffert, C., Trocme, C., Schäppi, M., Herrmann, F.R. \& Krause, K.H. (2007). NOX1 deficiency protects from aortic dissection in response to angiotensin II. Hypertension, 50, 189-196, ISSN 0194-911X

Go, Y.M. \& Jones, D.P. (2010) Redox control systems in the nucleus: mechanisms and functions. Antioxidants and Redox Signaling, 13, 489-509

Goyal, P., Weissmann, N., Grimminger, F., Hegel, C., Bader, L., Rose, F., Fink, L., Ghofrani, H.A., Schermuly, R.T., Schmidt, H.H., Seeger, W. \& Hänze, J. (2004). Upregulation of $\mathrm{NAD}(\mathrm{P}) \mathrm{H}$ oxidase 1 in hypoxia activates hypoxia-inducible factor 1 via increase in reactive oxygen species. Free Radical Biology and Medicine, 36, 1279-1288, ISSN 0891-5849

Gu, J.L., Pei, H., Thomas, L., Nadler, J.L., Rossi, J.J., Lanting, L. \& Natarajan R. (2001). Ribozyme-mediated inhibition of rat leukocyte-type 12-lipoxygenase prevents intimal hyperplasia in balloon-injured rat carotid arteries. Circulation, 103, 1446 1452, ISSN 0009-7330

Guzik, T.J., Chen, W., Gongora, M.C., Guzik, B., Lob, H.E., Mangalat, D., Hoch, N., Dikalov, S., Rudzinski, P., Kapelak, B., Sadowski, J. \& Harrison, D.G. (2008). Calciumdependent NOX5 nicotinamide adenine dinucleotide phosphate oxidase contributes to vascular oxidative stress in human coronary artery disease. Journal of the American College of Cardiology, 52, 1803-1809, ISSN 0735-1097

Guzik, T.J., West, N.E., Black, E., McDonald, D., Ratnatunga, C., Pillai, R. \& Channon, K.M. (2000). Functional effect of the C242T polymorphism in the $\mathrm{NAD}(\mathrm{P}) \mathrm{H}$ oxidase p22phox gene on vascular superoxide production in atherosclerosis. Circulation, 102, 1744-1747, ISSN 0009-7322

Harrison, D., Griendling, K.K., Landmesser, U., Hornig, B. \& Drexler H. (2003). Role of oxidative stress in atherosclerosis. American Journal of Cardiology, 91, 7A-11A, ISSN ISSN 0002-9149

Hazen, S.L., Gaut, J.P., Hsu, F.F., Crowley, J.R., d'Avignon, A. \& Heinecke, J.W. (1997). pHydroxyphenylacetaldehyde, the major product of L-tyrosine oxidation by the myeloperoxidase- $\mathrm{H}_{2} \mathrm{O}_{2}$-chloride system of phagocytes, covalently modifies epsilonamino groups of protein lysine residues. Journal of Biological Chemistry, 272, 1699016998, ISSN 0021-9258 
Heistad, D.D., Wakisaka, Y., Miller, J., Chu, Y. \& Pena-Silva, R. (2009). Novel aspects of oxidative stress in cardiovascular diseases. Circulation Journal 73, 201-207, ISSN 1346-9843

Hoyal, C.R., Gutierrez, A., Young, B.M., Catz, S.D., Lin, J.H., Tsichlis, P.N. \& Babior, B.M. (2003). Modulation of p47PHOX activity by sitespecific phosphorylation: Aktdependent activation of the NADPH oxidase. Proceedings of the National Academy of Sciences USA, 100, 5130-5135, ISSN 0027-8424

Hwang, J., Saha, A., Boo, Y.C., Sorescu, G.P., McNally, J.S., Holland, S.M., Dikalov, S., Giddens, D.P., Griendling, K.K., Harrison, D.G. \& Jo, H. (2003). Oscillatory shear stress stimulates endothelial production of O2- from p47phox-dependent NAD $(\mathrm{P}) \mathrm{H}$ oxidases, leading to monocyte adhesion. Journal of Biological Chemistry, 278, 4729147298, ISSN 0021-9258

Inoue, N., Kawashima, S., Kanazawa, K., Yamada, S., Akita, H. \& Yokoyama, M. (1998). Polymorphism of the NADH/NADPH oxidase p22phox gene in patients with coronary artery disease. Circulation, 97, 135-137, ISSN 0009-7322

Janiszewski, M., Lopes, L.R., Carmo, A.O., Pedro, M.A., Brandes, R.P., Santos, C.X. \& Laurindo, F.R. (2005). Regulation of $\mathrm{NAD}(\mathrm{P}) \mathrm{H}$ oxidase by associated protein disulfide isomerase in vascular smooth muscle cells. Journal of Biological Chemistry, 280, 40813-40819, ISSN 0021-9258

Kakar, R., Kautz, B. \& Eklund, E.A. (2005). JAK2 is necessary and sufficient for interferongamma-induced transcription of the gene encoding gp91PHOX. Journal of Leukocyte Biology, 77, 120-127, ISSN 0741-5400

Katsuyama, M., Fan, C., Arakawa, N., Nishinaka, T., Miyagishi, M., Taira, K. \& YabeNishimura, C. (2005). Essential role of ATF-1 in induction of NOX1, a catalytic subunit of NADPH oxidase: involvement of mitochondrial respiratory chain. Biochemical Journal, 386, 255-261, ISSN 0264-6021

Kawahara, T., Ritsick, D., Cheng, G. \& Lambeth, J.D. (2005). Point mutations in the prolinerich region of p22phox are dominant inhibitors of Nox1- and Nox2-dependent reactive oxygen generation. Journal of Biological Chemistry, 280, 31859-31869, ISSN 0021-9258

Kilpatrick, L. E., Sun S., Li, H., Vary, T.C. \& Korchak, H.M. (2010). Regulation of TNFinduced oxygen radical production in human neutrophils: role of delta-PKC. Journal of Leukocyte Biology, 87, 153-164, ISSN 0741-5400

Kondo, T., Hirose, M. \& Kageyama, K. (2009). Roles of oxidative stress and redox regulation in atherosclerosis. Journal of Atherosclerosis and Thrombosis, 16, 532-538

Kuroda, J. \& Sadoshima, J. (2010). NADPH oxidase and cardiac failure. Journal of Cardiovascular Translational Research, 3, 314-320

Lambeth J. D. (2004). NOX enzymes and the biology of reactive oxygen. Nature Reviews Immunology, 4, 181-189, ISSN 1474-1733

Lambeth, J.D. (2007). Nox enzymes, ROS, and chronic disease: an example of antagonistic pleiotropy. Free Radical Biology and Medicine, 43, 332-347, ISSN 0891-5849

Lassègue, B. \& Griendling, K.K. (2002). Out phoxing the endothelium: what's left without p47? Circulation Research, 90, 123-124, ISSN 0009-7330 
Lee, M.Y. \& Griendling, K.K. (2008). Redox signaling, vascular function, and hypertension. Antioxidant and Redox Signaling, 10, 1045-1059

Lee, M.Y., San Martin, A., Mehta, P.K., Dikalova, A.E., Garrido, A.M., Datla, S.R., Lyons, E., Krause, K.H., Banfi, B., Lambeth, J.D., Lassègue, B. \& Griendling, K.K. (2009). Mechanisms of vascular smooth muscle NADPH oxidase 1 (Nox1) contribution to injury-induced neointimal formation. Arteriosclerosis Thrombosis and Vascular Biology, 29, 480-487, ISSN 1079-5642

Leeuwenburgh, C., Rasmussen, J.E., Hsu, F.F., Mueller, D.M., Pennathur, S. \& Heinecke, J.W. (1997). Mass spectrometric quantification of markers for protein oxidation by tyrosyl radical, copper, and hydroxyl radical in low density lipoprotein isolated from human atherosclerotic plaques. Journal of Biological Chemistry, 272, 3520-3526, ISSN 0021-9258

Li, J.M. \& Shah, A.M. (2003). Mechanism of endothelial cell NADPH oxidase activation by angiotensin II. Role of the p47phox subunit. Journal of Biological Chemistry, 278, 12094-12100, ISSN 0021-9258

Lim, S.C., Goh, S.K., Lai, Y.R., Tee, W.W., Koh, A., Xu, X.H., Wu, Y.S., Yap, E., Subramaniam, T. \& Sum, C.F. (2006). Relationship between common functional polymorphisms of the p22phox gene (-930A $>\mathrm{G}$ and $+242 \mathrm{C}>\mathrm{T})$ and nephropathy as a result of Type 2 diabetes in a Chinese population. Diabetic Medicine, 23, 10371041, ISSN 0742-3071

Liu, H., Colavitti, R., Rovira, I.I. \& Finkel, T. (2005). Redox-dependent transcriptional regulation. Circulation Research, 97, 967-974, ISSN 0009-7330

Lyle, A.N., Deshpande, N.N., Taniyama, Y., Seidel-Rogol, B., Pounkova, L., Du, P., Papaharalambus, C., Lassègue, B. \& Griendling, K.K. (2009). Poldip2, a novel regulator of Nox4 and cytoskeletal integrity in vascular smooth muscle cells. Circulation Research, 105, 249-259, ISSN 0009-7330

Madamanchi N.R., Vendrov, A. \& Runge M.S. (2005). Oxidative stress and vascular disease. Arteriosclerosis Thrombosis and Vascular Biology, 25, 29-38, ISSN 1079-5642

Maitra, U., Singh, N., Gan, L., Ringwood, L. \& Li, L. (2009) IRAK-1 contributes to lipopolysaccharide-induced reactive oxygen species generation in macrophages by inducing NOX-1 transcription and Rac1 activation and suppressing the expression of antioxidative enzymes. Journal of Biological Chemistry, 284, 35403-35411, ISSN ISSN 0021-9258

Manea, A. (2010). NADPH oxidase-derived reactive oxygen species: involvement in vascular physiology and pathology. Cell and Tissue Research, 342, 325-339, ISSN 0302-766X

Manea, A., Manea, S.A., Gafencu, A.V. \& Raicu, M. (2007). Regulation of NADPH oxidase subunit p22(phox) by NF-kB in human aortic smooth muscle cells. Archives of Physiology and Biochemistry, 113, 163-172, ISSN

Manea, A., Manea, S.A., Gafencu, A.V., Raicu, M. \& Simionescu, M. (2008). AP-1-dependent transcriptional regulation of NADPH oxidase in human aortic smooth muscle cells: role of p22phox subunit. Arteriosclerosis Thrombosis and Vascular Biology, 28, 878-885, ISSN 1079-5642

Manea, A., Manea, S.A., Gafencu, A.V., Raicu, M. \& Simionescu, M. (2008). AP-1-dependent transcriptional regulation of NADPH oxidase in human aortic smooth muscle cells: 
role of p22phox subunit. Arteriosclerosis Thrombosis and Vascular Biology, 28, 878-885, ISSN 1079-5642

Manea, A., Raicu, M. \& Simionescu, M. (2005). Expression of functionally phagocyte-type $\mathrm{NAD}(\mathrm{P}) \mathrm{H}$ oxidase in pericytes: effect of angiotensin II and high glucose. Biology of the Cell, 97, 723-734, ISSN 1059-1524

Manea, A., Tanase, L.I., Raicu, M. \& Simionescu, M. (2010b). Transcriptional regulation of NADPH oxidase isoforms, Nox1 and Nox4, by nuclear factor-kappaB in human aortic smooth muscle cells. Biochemical and Biophysical Research Communications, 396, 901-907, ISSN 0006-291X

Manea, A., Tanase, L.I., Raicu, M. \& Simionescu, M. (2010a). Jak/STAT signaling pathway regulates Nox1 and Nox4-based NADPH oxidase in human aortic smooth muscle cells. Arteriosclerosis Thrombosis and Vascular Biology, 30, 105-112, ISSN 1079-5642

Martinet, W., Knaapen, M.W., De Meyer, G.R., Herman, A.G. \& Kockx, M.M. (2001). Oxidative DNA damage and repair in experimental atherosclerosis are reversed by dietary lipid lowering. Circulation Research, 88, 733-739, ISSN 0009-7330

Martinez-Hervas, S., Real, J.T., Ivorra, C., Priego, A., Chaves, F.J., Pallardo, F.V., Viña, J.R., Redon, J., Carmena, R. \& Ascaso J.F. (2010). Increased plasma xanthine oxidase activity is related to nuclear factor kappa beta activation and inflammatory markers in familial combined hyperlipidemia. Nutrition, Metabolism $\mathcal{E}$ Cardiovascular Diseases, 20, 734-739, ISSN 0939-4753

Matsuno, K., Yamada, H., Iwata, K., Jin, D., Katsuyama, M., Matsuki, M., Takai, S., Yamanishi, K., Miyazaki, M., Matsubara, H. \& Yabe-Nishimura, C. (2005). Nox1 is involved in angiotensin II-mediated hypertension: a study in Nox1-deficient mice. Circulation, 112, 2677-2685, ISSN

Miller, F.J. Jr., Filali, M., Huss, G.J., Stanic, B., Chamseddine, A., Barna, T.J. \& Lamb, F.S. (2007). Cytokine activation of nuclear factor kappa B in vascular smooth muscle cells requires signaling endosomes containing Nox1 and ClC-3. Circulation Research, 101, 663-671, ISSN 0009-7330

Moreno, M.U., San José, G., Fortuño, A., Beloqui, O., Redón, J., Chaves, F.J., Corella, D., Díez, J. \& Zalba, G. (2007). A novel CYBA variant, the $-675 \mathrm{~A} / \mathrm{T}$ polymorphism, is associated with essential hypertension. Journal of Hypertension, 25, 1620-1626, ISSN

Nakashima, Y., Plump, A.S., Raines, E.W., Breslow, J.L. \& Ross, R. (1994). ApoE-deficient mice develop lesions of all phases of atherosclerosis throughout the arterial tree. Arteriosclerosis, Thrombosis, and Vascular Biology, 14, 133-140, ISSN

Negre-Salvayre, A., Auge, N., Ayala, V., Basaga, H., Boada, J., Brenke, R., Chapple, S., Cohen, G., Feher, J., Grune, T., Lengyel, G., Mann, G.E., Pamplona, R., Poli, G., Portero-Otin, M., Riahi, Y., Salvayre, R., Sasson, S., Serrano, J., Shamni, O., Siems, W., Siow, R.C., Wiswedel, I., Zarkovic K. \& Zarkovic, N. (2010). Pathological aspects of lipid peroxidation. Free Radical Research, 44, 1125-1171, ISSN 1071-5762

Ni, W., Zhan, Y., He, H., Maynard, E., Balschi, J.A. \& Oettgen, P. (2007). Ets-1 is a critical transcriptional regulator of reactive oxygen species and p47(phox) gene expression in response to angiotensin II. Circulation Research, 101, 985-994, ISSN 0009-7330

Olukman, M., Orhan, C.E., Celenk, F.G. \& Ulker, S. (2010). Apocynin restores endothelial dysfunction in streptozotocin diabetic rats through regulation of nitric oxide 
synthase and NADPH oxidase expressions. Journal of Diabetes and its Complications, 24, 415-423, ISSN 1056-8727

Pendyala, S. \& Natarajan, V. (2010). Redox regulation of Nox proteins. Respiratory Physiology \& Neurobiology,174, 265-271, ISSN 1569-9048

Raicu, M. \& Manea, A. (2010). Activator protein-1 regulates Nox1 and Nox4-containing NADPH oxidase transcription in human vascular smooth muscle cells. Annals of $R S C B, \mathrm{XV}, 11-17$

Ray, R., Murdoch, C.E., Wang, M., Santos, C.X., Zhang, M., Alom-Ruiz, S., Anilkumar, N., Ouattara, A., Cave, A.C., Walker, S.J., Grieve, D.J., Charles, R.L., Eaton, P., Brewer, A.C. \& Shah, A.M. (2011). Endothelial Nox4 NADPH oxidase enhances vasodilatation and reduces blood pressure in vivo. Arteriosclerosis Thrombosis and Vascular Biology, 31, 1368-1376, ISSN 1079-5642

Riahi, Y., Cohen, G., Shamni, O. \& Sasson, S. (2010). Signaling and cytotoxic functions of 4hydroxyalkenals. American Journal of Physiology Endocrinology and Metabolism, 299, 879-886, ISSN 0193-1849

San José, G., Fortuño, A., Beloqui, O., Díez, J. \& Zalba, G. (2008). NADPH oxidase CYBA polymorphisms, oxidative stress and cardiovascular diseases. Clinical Science (Lond), 114, 173-182, ISSN 0143-5221

Savenkova, M.L., Mueller, D.M. \& Heinecke, J.W. (1994). Tyrosyl radical generated by myeloperoxidase is a physiological catalyst for the initiation of lipid peroxidation in low density lipoprotein. Journal of Biological Chemistry, 269, 20394-20400, ISSN 0021-9258

Sedeek, M., Hébert, R.L., Kennedy, C.R., Burns, K.D. \& Touyz, R.M. (2009). Molecular mechanisms of hypertension: role of Nox family NADPH oxidases. Current Opinion in Nephrology and Hypertension, 18, 122-127, ISSN 0194-911X

Serrander, L., Jaquet, V., Bedard, K., Plastre, O., Hartley, O., Arnaudeau, S., Demaurex, N., Schlegel, W. \& Krause, K.H. (2007). NOX5 is expressed at the plasma membrane and generates superoxide in response to protein kinase $C$ activation. Biochimie, 89, 1159-1167, ISSN 0300-9084

Shao, B. \& Heinecke, J.W. (2009). HDL, lipid peroxidation, and atherosclerosis. Journal of Lipid Research, 50, 599-601, ISSN 0022-2275

Shao, B. \& Heinecke, J.W. (2009). HDL, lipid peroxidation, and atherosclerosis. Journal of Lipid Research 50, 599-601, ISSN 0022-2275

Sima, A.V., Stancu, C.S. \& Simionescu, M. (2009). Vascular endothelium in atherosclerosis. Cell and Tissue Research, 335, 191-203, ISSN 0302-766X

Simionescu, M. (2007). Implications of early structural-functional changes in the endothelium for vascular disease. Arteriosclerosis Thrombosis and Vascular Biology, 27, 266-274, ISSN 1079-5642

Simionescu, M., Popov, D. \& Sima, A. (2009). Endothelial transcytosis in health and disease. Cell and Tissue Research, 335, 27-40, ISSN 0302-766X

Tabet, F., Schiffrin, E.L., Callera, G.E., He, Y., Yao, G., Ostman, A., Kappert, K., Tonks, N.K. \& Touyz, R.M. (2008). Redox-sensitive signaling by angiotensin II involves oxidative inactivation and blunted phosphorylation of protein tyrosine 
phosphatase SHP-2 in vascular smooth muscle cells from SHR. Circulation Research, 103, 149-158, ISSN 0009-7330

Tonks, N.K. (2006). Protein tyrosine phosphatases: from genes, to function, to disease. Nature Reviews Molecular Cell Biology, 7, 833-846, ISSN 1471-0072

Touyz, R.M. (2003) Reactive oxygen species in vascular biology: role in arterial hypertension. Expert Review of Cardiovascular Therapy, 1, 91-106

Turrens, J.F. (2003). Mitochondrial formation of reactive oxygen species. Journal of Physiology, 552, 335-344, ISSN 0022-3751

Valdivia, A., Pérez-Alvarez, S., Aroca-Aguilar, J.D., Ikuta, I. \& Jordán, J. (2009). Superoxide dismutases: a physiopharmacological update. Journal of Physiology and Biochemistry, 65, 195-208, ISSN 1138-7548

Vendrov, A.E., Hakim, Z.S., Madamanchi, N.R., Rojas, M., Madamanchi, C. \& Runge, M.S. (2007). Atherosclerosis is attenuated by limiting superoxide generation in both macrophages and vessel wall cells. Arteriosclerosis Thrombosis and Vascular Biology, 27, 2714-2721, ISSN 1079-5642

Vendrov, A.E., Hakim, Z.S., Madamanchi, N.R., Rojas, M., Madamanchi, C. \& Runge, M.S. (2007). Atherosclerosis is attenuated by limiting superoxide generation in both macrophages and vessel wall cells. Arteriosclerosis Thrombosis and Vascular Biology, 27, 2714-2721, ISSN 1079-5642

Woo, H.A., Yim, S.H., Shin, D.H., Kang, D., Yu, D.Y. \& Rhee, S.G. (2010). Inactivation of peroxiredoxin I by phosphorylation allows localized $\mathrm{H}(2) \mathrm{O}(2)$ accumulation for cell signaling. Cell, 140, 517-528, ISSN 0092-8674

Wu, W.S., Wu, J.R. \& Hu, C.T. (2008). Signal cross talks for sustained MAPK activation and cell migration: the potential role of reactive oxygen species. Cancer Metastasis Rev, 27, 303-314

Xu, X., Gao, X., Potter, B.J., Cao, J.M. \& Zhang, C. (2007). Anti-LOX-1 rescues endothelial function in coronary arterioles in atherosclerotic ApoE knockout mice. Arteriosclerosis Thrombosis and Vascular Biology, 27, 871-877, ISSN 1079-5642

Yamamori, T., Inanami, O., Nagahata, H. \& Kuwabara, M. (2004). Phosphoinositide 3-kinase regulates the phosphorylation of NADPH oxidase component p47(phox) by controlling cPKC/PKCdelta but not Akt. Biochemical and Biophysical Research Communications, 316, 720-730, ISSN 0006-291X

Yusuf, S., Dagenais, G., Pogue, J., Bosch, J., \& Sleight, P. (2000) Vitamin E supplementation and cardiovascular events in high-risk patients. The Heart Outcomes Prevention Evaluation Study Investigators. New England Journal of Medicine, 342, 154-160, ISSN 0028-4793

Zadák, Z., Hyspler, R., Tichá, A., Hronek, M., Fikrová, P., Rathouská, J., Hrnciariková, D. \& Stetina, R. (2009). Antioxidants and vitamins in clinical conditions. Physiological Research, 58, 13-17, ISSN 0862-8408

Zalba, G., Fortuño, A., San José, G., Moreno, M.U., Beloqui, O. \& Díez, J. (2007). Oxidative stress, endothelial dysfunction and cerebrovascular disease. Cerebrovascular Diseases 24, 24-29, ISSN 1015-9770 
Zhang, L., Sheppard, O.R., Shah, A.M. \& Brewer, A.C. (2008). Positive regulation of the NADPH oxidase NOX4 promoter in vascular smooth muscle cells by E2F. Free Radical Biology and Medicine, 45, 679-685, ISSN 0891-5849

Zhang, M., Brewer, A.C., Schröder, K., Santos, C.X., Grieve, D.J., Wang, M., Anilkumar, N., Yu, B., Dong, X., Walker, S.J., Brandes, R.P. \& Shah, A.M. (2010). NADPH oxidase4 mediates protection against chronic load-induced stress in mouse hearts by enhancing angiogenesis. Proceedings of the National Academy of Sciences USA, 107, 18121-18126, ISSN 0027-8424 


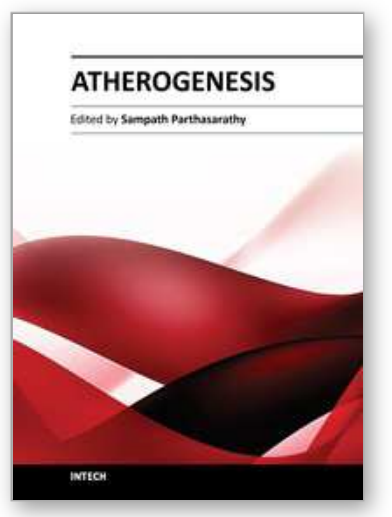

\author{
Atherogenesis \\ Edited by Prof. Sampath Parthasarathy
}

ISBN 978-953-307-992-9

Hard cover, 570 pages

Publisher InTech

Published online 11, January, 2012

Published in print edition January, 2012

This monograph will bring out the state-of-the-art advances in the dynamics of cholesterol transport and will address several important issues that pertain to oxidative stress and inflammation. The book is divided into three major sections. The book will offer insights into the roles of specific cytokines, inflammation, and oxidative stress in atherosclerosis and is intended for new researchers who are curious about atherosclerosis as well as for established senior researchers and clinicians who would be interested in novel findings that may link various aspects of the disease.

\title{
How to reference
}

In order to correctly reference this scholarly work, feel free to copy and paste the following:

Adrian Manea (2012). Vascular Biology of Reactive Oxygen Species and NADPH Oxidases: Role in Atherogenesis, Atherogenesis, Prof. Sampath Parthasarathy (Ed.), ISBN: 978-953-307-992-9, InTech, Available from: http://www.intechopen.com/books/atherogenesis/vascular-biology-of-reactive-oxygen-speciesand-nadph-oxidases-role-in-atherogenesis

\section{INTECH}

open science / open minds

\section{InTech Europe}

University Campus STeP Ri

Slavka Krautzeka 83/A

51000 Rijeka, Croatia

Phone: +385 (51) 770447

Fax: +385 (51) 686166

www.intechopen.com

\section{InTech China}

Unit 405, Office Block, Hotel Equatorial Shanghai

No.65, Yan An Road (West), Shanghai, 200040, China

中国上海市延安西路65号上海国际贵都大饭店办公楼405单元

Phone: +86-21-62489820

Fax: +86-21-62489821 
(C) 2012 The Author(s). Licensee IntechOpen. This is an open access article distributed under the terms of the Creative Commons Attribution 3.0 License, which permits unrestricted use, distribution, and reproduction in any medium, provided the original work is properly cited. 